\title{
Suitability of Polyvinyle Cinnamate Photo-resists For Graticule Production
}

\author{
P. K. JAIN AND J. PRASAD \\ Central Scientific Instruments Organisation, Chandigarh \\ (Received May 26, 1973)
}

Photographic methods employing photo-resist or photo-emulsion as light sensitive layer are well established [1-3] for mass production of graticule and fine scales. Photo-resist compositions based on bi-chromated organic colloid, and phenolformaldehyde have already been reported $[3,4]$ by us.

In the present note, we report results of our preliminary trials on the use of polyvinyl cinnamate photo-resist in graticulation work.

The photo-resist was made by mixing polyvinyl alcohol, pyridine, and cinnamoyl chloriode in requisite proportions and following largely the synthesis method described by Minsk et al [5].

With the photo-resist thus made experiments were conducted to reproduce Itek resolution chart. It was found that resolution of the order of 200 lines/mm could be obtained using this photo-resist, Its resistivity of HF vapors is perfect resulting in clear substrate free from any surface blemishes.

For the reasons already outlined and also because differential solubility of exposed and unexposed portions is more in case of polyvinyl cinnamate photo-resist, it is considered superior to either bichromated organic colloid or phenolformaldehyde based photo resists.

Further work is in progress for evaluating the sensitivity of polyvinyl cinnamate photo-resist, improving its speed/efficviency, and optimising its compositions for use in production of graticules and micro-circuits.

The authors are grateful to Prof. Harsh Vardhan, Director of the Organisation, for his keen interest and permission to present this note. Thanks are also due to Mr. Nanu Ram for assistance in experiments.

\section{REFERENCES}

1. E. Bovey, J. Sci. Instrm, 39, 405 (1962).

2. J. Prasad and P. K. Jain, Research and Industry, 14, 57 (1969).

3. P. K. Jain and J. Prasad, Bull Opt. Soc. India, 3, 28 (1969).

4. J. Prasad and P. K. Jain, Research and Industry, 17, 4(1972)

5. L. M. Minsk, J. G. Smith, W. P. V. Deusen, and J. F. Wright, J.Appl. Polymer Sci, 11, 302 (1959). 